\title{
The impact of the learning contract on self-directed learning and satisfaction in nursing students in a clinical setting
}

\author{
Mahboobeh Sajadi ${ }^{1}$, Neda Fayazi ${ }^{2}$, Andrew Fournier ${ }^{3}$, Ahmad Reza Abedi* ${ }^{4 *}$ \\ Received: 22 Feb 2017 \\ Published: 7 Dec 2017
}

\begin{abstract}
Background: The most important responsibilities of an education system are to create self-directed learning opportunities and develop the required skills for taking the responsibility for change. The present study aimed at determining the impact of a learning contract on self-directed learning and satisfaction of nursing students.

Methods: A total of 59 nursing students participated in this experimental study. They were divided into six 10-member groups. To control the communications among the groups, the first 3 groups were trained using conventional learning methods and the second 3 groups using learning contract method. In the first session, a pretest was performed based on educational objectives. At the end of the training, the students in each group completed the questionnaires of self-directed learning and satisfaction. The results of descriptive and inferential statistical methods (dependent and independent $t$ tests) were presented using SPSS.

Results: There were no significant differences between the 2 groups in gender, grade point average of previous years, and interest toward nursing. However, the results revealed a significant difference between the 2 groups in the total score of self-directed learning $(\mathrm{p}=0.019)$. Although the mean satisfaction score was higher in the intervention group, the difference was not statistically significant.

Conclusion: This study suggested that the use of learning contract method in clinical settings enhances self-directed learning among nursing students. Because this model focuses on individual differences, the researcher highly recommends the application of this new method to educators.
\end{abstract}

Keywords: Clinical teaching, Learning contract, Self-directed learning, Learning Methods, Training, Autonomous learning, Education, Active learning, self-confidence, Training activity \& support, Collaborative learning

Copyright $₫$ Iran University of Medical Sciences

Cite this article as: Sajadi M, Fayazi N, Fournier A, Abedi AR. The impact of the learning contract on self-directed learning and satisfaction in nursing students in a clinical setting. Med J Islam Repub Iran. 2017 (7 Dec);31:72. https://doi.org/10.14196/mjiri.31.72

\section{Introduction}

Nursing education places an emphasis on achieving the ultimate goal of education, i.e. competence and efficiency in various aspects and meeting the clients' care needs (1-3).

Corresponding author: Ahmad Reza Abedi, abedi.a@arakmu.ac.ir

1. Academic Member of Pediatrics Nursing Department, School of Nursing \& Midwifery, Arak University of Medical Sciences, Arak, Iran.

2. Academic Member of Saveh University of Medical Sciences, Kaveh Industrial Estate Company, Saveh, Iran.

3. College of Doctoral Studies, Grand Canyon University, Phoenix, Arizona, USA

4. Academic Member of Traditional and Complementary Medicine Research Center, Department of Medical - Surgical, School of Nursing \& Midwifery, Arak University of Medical Sciences, Arak, Iran.
Several studies have suggested that current nursing education has numerous deficiencies and shortages and might not meet the learning requirements of nursing students (4-7).

$\uparrow$ What is "already known" in this topic:

Use of new educational methods for improving competence and efficiency of learners is inevitable. The traditional approach in the field of education has numerous deficiencies and shortages and has not been designed according to the active learning involvement.

$\rightarrow$ What this article adds:

The use of new learning styles such as LCs in a field setting may lead to SDL. This method nurtures in-depth learning and encourages students to learn independently. As this method focuses on individual differences, theoretical-based learning in adults, and strengthening SDL its implementation is highly recommended for nursing educators. 
Therefore, assessing and applying new educational approaches seem necessary $(8,9)$. During the past decades, educators and instructors have used various approaches to transform the learning procedure to self-directed learning (SDL) methods (10-12). Collaborative learning has been formed according to these efforts and made common in many countries (13). Collaborative learning adapts educational activities with the learners' needs (14). Thus, students will be responsible for their own learning (15).

Some experts believe that the most important responsibility of the education system in this rapidly changing world and short half-life of knowledge in medical studies is to require educators to establish SDL opportunities in the safe environment of universities rather than provide a plethora of knowledge $(16,17)$. Moreover, they must provide the necessary facilities and requirements for developing the required skills and take responsibility for change $(18,19)$. Health care education, which has not been designed according to the active involvement of learning, will not persuade students to take responsibility for their own learning independent of educators and teachers (10). More traditional methods of education will also encounter shortages in preparing professional health team members (20).

The need to change from teacher-centered styles to student-centered styles was a valuable part of the education system for a long time, allowing students to participate in learning experiences. Encouraging the active role of the learner in learning fostered a deeper level of learning and enhanced the self-directed capacity and innovation that eventually increased the self-confidence and pervasive accomplishments of learners $(21,22)$.

One approach to SDL is a learning contract (LC) (21). Nowadays, in some developed countries, many educators encourage nursing students toward SDL by LCs (23). LCs have allowed much success among nurses in their professional development goals, distance education, and education-based services (24).

Most advocates of the contract learning method emphasize the benefits of individualizing the learning process, which promotes the learner's independence, develops lifelong learning behaviors, and results in active participation of the learner (25).

LC is a method of learning and a reciprocal arrangement between the instructor and student to achieve educational goals (20). LC is a learner-centered activity that helps students relate what they learn in class with what they see in clinical practice, and this activity may lead to integration of theory and practice (26). Since then, there has been a considerable increase in supporting the benefits of using LCs in nursing education in the literature, many of which are about inducing self-confidence and pervasive possession. However, less literature exists on the reliability rating of LCs (21). LCs can foster the change of power and authority from the instructor to the leaner. Most of the accounted LCs described in various studies are concerned with a more traditional and conventional approach toward LCs, a process which begins with the learners writing down the learning objectives $(10,27)$. Researchers used many terms to describe LCs, terms, which concentrated on the participation of learners in the learning process. Some of these terms are learning programs, studying plans, learning agreements, and learning recommendations (28).

Various health care professions such as medicine, nursing, and radiology technologists have used LCs (29). Cross has proposed one of the rare studies in this field and suggested that contract learning is an efficient tool for facilitating learning and enhancing students' clinical experience value (30).

Despite the positive features of LCs, Tsang et al. referred to several issues in running the LCs in the occupational therapy profession in Hong Kong. Many of their learners believed writing LCs were difficult and most of the learners wrote contracts with identical context and content. To pass the courses and ensure a high score, some students wrote objectives with fewer requirements than others (31).

According to Tsang, "negative scores may be due to perceived cultural differences between Western vs. Asian students toward educators." Tsang found that providing sufficient education by supervisors or clinical seniors, appropriate counseling, and couching for learners might facilitate SDL by LCs and may be a positive experience for the process owners (31). Given the results of the literature review, the present study aimed at identifying the impact of a LC on SDL and the satisfaction of nursing students.

\section{Methods}

This study was conducted at Tehran University of Medical Sciences (TUMS) under the following ethical license: \# 13895/12-02-90. The researchers used a 2-group experimental study design. The participants included all the nursing students of the same academic year, who have taken the pediatrics apprenticeship course. First, the students completed the demographic characteristic form, and they were then divided into six 10-member groups. All observed trainings and apprenticeship within the education department took place in 9 sessions from 7:30 a.m. to 1:00 p.m. To control any relationship between the groups, the first 3 groups were trained conventionally and the second 3 groups by LCs. The education processes and procedures, course objectives (course plans), scientific references, and literatures were described for the 2 groups. The educators of the 2 groups were comparable in their clinical and teaching experience and interest in the course.

1. Intervention group: The researchers performed a pretest to identify the students' educational needs according to the educational objectives. A contract was signed between the educator and each of the students based on the test results. In each session, students chose a specific patient based on the educational objectives or lesson plans of that particular session and examined the patient accurately (eg, medical history and physical examinations). Then, the students addressed the test results, diagnostic tests, medications, and all actions made for the patient. Each student separately prepared a patient description in the form of a scenario based on the collected information. Meanwhile, the students accessed the library and the internet when faced with a problem. As this was the students' first experience with this method, the educator reviewed the students' achievement rate of daily objectives and tried to guide them 
accordingly. At the end of the day, the educator asked questions about the patient, induced the students to think, and provided them with the opportunity to solve the problem before the due date. In the second week, the contract could be changed according to the pervasive weaknesses and strengths, if necessary. Students completed 2 questionnaires at the end of the clinical practice.

2. Conventional education group: In this group, researchers provided the same traditional educational methods in a clinical setting such as patient care, nursing processes, and the bedside teaching. Each student was given a patient each day and examined his or her own patient. The educator solved the students' problems and corrected their incomplete information and scientific issues. Then, a health care and educational plan was made for the patient according to the information collected through physical examinations, the patient's history, test results, and diagnostic tests.

At the end of the training course, students in both groups completed self-directed and satisfactory inventories. The results were analyzed subsequently by descriptive and inferential statistical methods (dependent and independent $t$ tests) using SPSS 20 for Windows software (SPSS, Inc., Chicago, IL, USA).

\section{Results}

The findings of this study revealed that the age range of most participants $(78.6 \%)$ was 21 to 23 , while the overall age range was from 21 to 25 . All participants were single. Females comprised $87 \%(n=51)$ of the participants, and $42.4 \%(n=25)$ had an experience of working in a hospital during their undergraduate studies. All participants were single. From the 59 participants, researchers randomly assigned 24 participants to intervention and 35 to control groups.

This study revealed no significant differences between the 2 groups in grade point average (GPA); however, there was a significant difference between the 2 groups in age. Even though findings showed a significant difference between the 2 groups in age, the difference was less than a year and was not functionally significant (Table 1).

Table 2 demonstrates a significant difference in SDL scores between the intervention and control groups.

\section{Discussion}

The findings of the present study revealed that use of LCs in a clinical setting will lead to SDL in nursing students. Moreover, the results demonstrated a significant difference between the 2 groups in the total score of SDL $(p=0.019)$. O'Shea believed that SDL is necessary for nurses to deal with the challenging environment of the clinical care (32). The findings of previous studies revealed a positive attitude toward the development of the students' confidence and competence $(21,30,33,34)$. Timmins (29) believed that LCs are able to transform the learning process to the SDL and help students develop lifelong learning behaviors and practices. Well-designed LCs facilitate processes, allow the learner to control their own training, make more distinctions between clients, and concentrate on the clinical experiences in which the students are interested (29). Schroyen and Finlayson used LCs signed between nursing staff and nursing students and they found that a positive interaction was established between the 2 groups (34). In the students' view, this method allowed them to focus on their own learning in a specific area (33). This method nurtures in-depth learning and encourages students to learn independently. Consequently, students experience more independence when entering the teaching-learning process. The nature of LCs tends to increase student-teacher interaction, which has many advantages for students (30).

Comparison of the satisfaction rate of the 2 groups for the provided teaching methods indicated no significant difference between them. Ghazi and Henshaw suggested that students enjoy having the freedom to select their own studying method and organize their procedure (35). Bailey and Tuohy reviewed the nursing students' experiences of LCs with a thematic analysis; one of the obtained themes was the fear of taking responsibility for learning in some students (36). After applying LCs in a clinical setting and during the interviewing of students and educators, Chan and Wai-tong found that one of the problems in implementing the plan was taking the responsibility and accountability for learning (37). One of the reasons for dissatisfaction with this method might be unpreparedness and the limited time of the training course for achieving the goals, which increases the students' workload. Maxie and Pryce-Miller also emphasized the importance of preparing students in

Table 1. Comparison of mean age and GPA in intervention and control groups

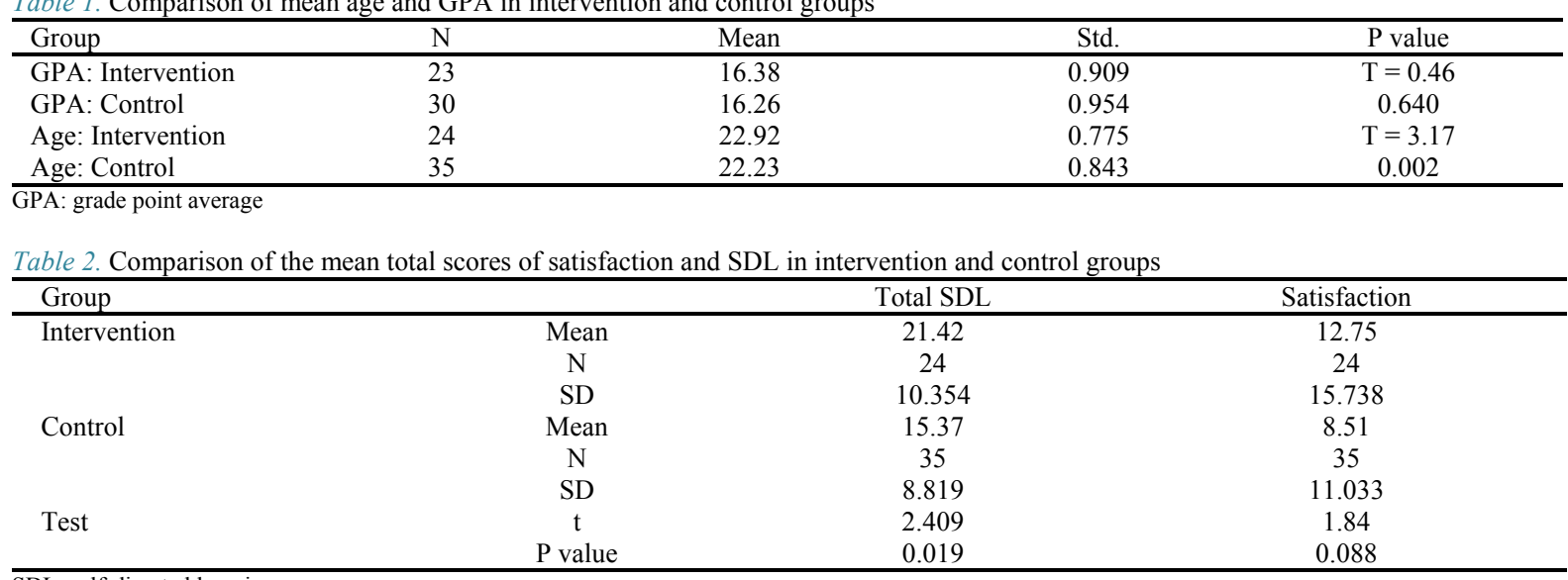

SDL: self-directed learning 
this respect (38).

The results revealed no correlation among age, rate of interest in the course, GPA of the previous years with satisfaction of teaching method and SDL. This was in accordance with the study results of El-Gilany et al. (39), and Cadorin et al. (40). The significant difference between the 2 groups in age could not and did not influence the study results.

Since learning styles have not been considered in the present study, it seems that further studies in this area are necessary. Despite the limitations of this method, in general, students trained with the LC method become independent, self-directed, confident, and motivated. Moreover, SDL method makes students think deeply about their practice and helps them concentrate on learning specific materials and problems. Effective use of contracts allows students to learn educational contents appropriately. The approach also enhances the opportunity for practical and creative innovation and responsibility, which are key elements in nursing. Detailed planning, commitment, student involvement, and adequate resources are necessary for this procedure. Finally, further studies are still needed in this field (32).

\section{Conclusion}

Use of LCs particularly enhances learning in nursing students and is a valuable tool in clinical settings. Because of this method's focus on individual differences, theoreticalbased learning in adults, and strengthened SDL, which is one of the aims of nursing in the 21 st century, implementation of this method is highly recommended to nursing educators. Nevertheless, one of the existing limitations is the unfamiliarity of some educators with this method, which can be solved during educational courses.

\section{Acknowledgments}

We gratefully acknowledge the TUMS for financial and scientific supervision and participation of nursing students in this research and finally Mrs. Zahra Roosta, instructor of the Khalij-e Fars Student's Research Center of Arak, for the educational collaboration.

\section{Conflict of Interests}

The authors declare that they have no competing interests.

\section{References}

1. Karimy, M., A.R. Abedi, H. Abredari, M. Taher, F. Zarei, and Z. Rezaie-Shahsavarloo. Does the theory-driven program affect the risky behavior of drug injecting users in a healthy city? A quasiexperimental study. Med J Islam Repub Iran. 2016;30(1):15-25.

2. Hibbert D, Al-Sanea NA, Balens JA. Perspectives on specialist nursing in saudi arabia: A national model for success. Ann Saudi Med. 2012;32(1):78-85.

3. Abedi A, Koohestani HR, Roosta Z. The short- term effect of chest physiotherapy on spirometric indices in chemical warfare victims exposed to mustard gas. Armaghane danesh. 2008;13(51-52):81-91.

4. Alfaris E, Abdulgader A, Alkhenizan A. Towards evidence-based medical education in saudi medical schools. Ann Saudi Med.2006;26(6):429.

5. Banning M. Approaches to teaching: Current opinions and related research. Nurse Education Today. 2005;25(7):502-508.

6. Abredari, H., F. Bolourchifard, M. Rassouli, N. Nasiri, M. Taher, and A. Abedi. Health locus of control and self-care behaviors in diabetic foot patients. Med J Islam Repub Iran. 2015;29(1):1083-1087.

7. Taher, M., Z. Safavi Bayat, K. Niromand Zandi, E. Ghasemi, H. Abredari, M. Karimy, et al. Correlation between compliance regimens with health locus of control in patients with hypertension. Med J Islam Repub Iran. 2015;29(0):194-0.

8. Baghcheghi, N., H.R. Koohestani, K. Rezaei, A. Seraji, and A.R. Abedi. Prevalence needlestick/sharps injuries among nursing student and related factor. Iran Occupational Health Journal. 2011;7(4):6-0.

9. Arzani A, Lotfi M, Abedi A. Experiences and clinical decision-making of operating room nurses based on benner's theory. Journal of Babol University Of Medical Sciences. 2016;18(4):35-40.

10. Azer SA. Medical education at the crossroads: Which way forward? Ann Saudi Med. 2007;27(3):153.

11. Araban, M., M. Karimy, M. Taher, S. Baiati, A. Bakhtiari, H. Abrehdari, et al. Predictors of tobacco use among medical students of ahvaz university: A study based on theory of planned behavior. J Educ Community Health. 2015;2(1):10-18.

12. Hosseini K, Alavi S, Abedi A. Reversibility of airflow obstruction in chronic obstructive pulmonary disease secondary to sulfur mustard gas injury. Arch Iran Med. 1999;2:178-80.

13. Taher, M., H. Abredari, M. Karimy, A. Abedi, and M. Shamsizadeh. The relation between social support and adherence to the treatment of hypertension. J Educ Community Health. 2014;1(3):59-67.

14. Karimy, M., A. Abedi, F. Aminshokravi , and S. Sadat Tavafian. Preventing hiv transmission among the opiate-dependent population in zarandieh: Evaluation of the hbm-based educational programs. Iranian Journal of Health Education \& Health Promotion. 2013;1(1):11.

15. Koohestani, H., N. Baghcheghi, K. Rezaei, A. Abedi, A. Seraji, and S. Zand. Occupational violence in nursing students in arak, iran Iranian Journal of Epidemiology. 2011.

16. Zakerinia, M., M. Namdar, S. Alavi, and A. Abedi Development of hematologic malignancies and aplastic anemia following exposure to mustard gas. MilMed Journal. 2002;4(3):157-161.

17. Heidari, S., M. Rezaei, M. Sajadi, N.M. Ajorpaz, and H.G. Koenig Religious practices and self-care in iranian patients with type 2 diabetes. Journal of Religion and Health. 2016:1-14.

18. Mcallister M. Learning contracts: An australian experience. Nurse education today. 1996;16(3):199-205.

19. Rakhimova DA, Talgatovna SZ, Abedi A. Influence of ozonotherapy on the functional status and medical aspects of quality of life in patients with bronchial asthma. International Research Journal of Medicine and Medical Sciences. 2015;3(1):17-21.

20. Beattie IVV, Collins B, Mcinnes B. Deep and surface learning: A simple or simplistic dichotomy? Accounting Education. 1997;6(1):112.

21. Rye KJB. Perceived benefits of the use of learning contracts to guide clinical education in respiratory care students. Respiratory care. 2008;53(11):1475-1481.

22. Rafii F, Sajadi Hezaveh M, Naiemeh Seyedfatemi N. Concept analysis of transition from nursing studentship to working life: A hybrid model. Journal of hayat. 2014;20(1):59-73.

23. Zakerinia, M., M. Namdar, S. Alavi, and A. Abedi Development of hematologic malignancies and aplastic anemia following exposure to mustard gas. Irn J Med Sci. 1998;23((1\&2)):5.

24. Moon DS. Impact of contract learning on learning to write in an eap class: Case studies of four international graduate students' experience. (Doctoral dissertation, University of Illinois at Urbana-Champaign). 2007: ProQuest.

25. Chien WT, Chan SWC, Morrissey J. The use of learning contracts in mental health nursing clinical placement: An action research. International Journal of Nursing Studies. 2002;39(7):685-694.

26. Boorim Nejad L. Learning contract: A method of teaching in nursing. Iranian Journal of Medical Education. 2012;11(7):696-700.

27. Sajadi, M., Z. Gholami, D. Hekmatpour, P. Soltani, and F. Haghverdi Cold dialysis solution for hemodialysis patients with fatigue. Iranian Journal of Kidney Diseases. 2016;10(5).

28. Barrington K, Street K. Learner contracts in nurse education: Interaction within the practice context. Nurse education in practice. 2009;9(2):109-118.

29. Timmins $F$. The usefulness of learning contracts in nurse education: The irish perspective. Nurse education in practice. 2002;2(3):190-196.

30. Cross V. Introducing learning contracts into physiotherapy clinical education. Physiotherapy. 1996;82(1):21-27.

31. Tsang HW, Paterson M, Packer TL. Self-directed learning in fieldwork education with learning contracts. British Journal of 
Therapy and Rehabilitation. 2002;9(5):184-189.

32. O'shea E. Self-directed learning in nurse education: A review of the literature. Journal of advanced nursing. 2003;43(1):62-70.

33. Idczak SE. I am a nurse: Nursing students learn the art and science of nursing. Nursing Education Perspectives. 2007;28(2):66-71.

34. Schroyen B, Finlayson M. Clinical teaching and learning: An action research study. Nursing Praxis in New Zealand. 2004;20:36-45.

35. Ghazi F, Henshaw L. How to keep student nurses motivated. Nursing Standard. 1998;13(8):43-48.

36. Bailey ME, Tuohy D. Student nurses' experiences of using a learning contract as a method of assessment. Nurse education today. 2009;29(7):758-762.

37. Chan SWC, Wai-Tong C. Implementing contract learning in a clinical context: Report on a study. Journal of Advanced Nursing. 2000;31(2): 298-305

38. Pryce-Miller M. Are first year undergraduate student nurses prepared for self directed learning? Self. 2010.

39. El-Gilany AH, Abusaad FES. Self-directed learning readiness and learning styles among saudi undergraduate nursing students. Nurse Education Today. 2013;33(9):1040-1044

40. Cadorin, L., N. Suter, A. Dante, S.N. Williamson, A. Devetti, and A. Palese Self-directed learning competence assessment within different healthcare professionals and amongst students in italy. Nurse education in practice. 2012;12(3):153-158. 